\title{
Complement Localization and Mediation of Ischemic Injury in Baboon Myocardium
}

\author{
R. Neal Pinckard, Robert A. O'Rourke, Michael H. Crawford, \\ Frederick S. Grover, Linda M. McManus, John J. Ghidoni, \\ S. Brandley Storrs, and Merle S. Olson, Departments of Pathology, \\ Medicine and Biochemistry, University of Texas Health Science Center \\ at San Antonio, Texas 78284
}

\begin{abstract}
A B S TRACT We sought to determine whether the third component of complement (C3) is localized in ischemic baboon myocardium after coronary artery ligation. Furthermore, we assessed the effects of prior C3 depletion on myocardial necrosis. We studied seven control baboons (group I) and seven C3-depleted (group II) baboons that were killed $24 \mathrm{~h}$ after ligation of the anterior descending coronary artery. Multiple tissue samples were obtained from infarct, intermediate, and normal myocardial sites as defined by serial unipolar epicardial ECG mapping. In group I baboons, myocardial creatine kinase content from infarct sites was reduced as compared with normal sites $(12.6 \pm 0.92[\mathrm{SE}]$ vs. $24.4 \pm 0.75 \mathrm{IU} / \mathrm{mg}$ protein, $P<0.001)$. The intermediate sites from group I contained more creatine kinase ( $19.0 \pm 1.25 \mathrm{IU} / \mathrm{mg}$ protein) than infarct sites $(P<0.001)$, but less $(P<0.025)$ than normal sites. In group II, intermediate sites showed no significant reduction in creatine kinase from normal sites and there was significantly less creatine kinase depletion in infarct sites when compared with group I animals $(33.7 \pm 4.6$ and $51.4 \pm 1.8 \%$ depletion, respectively, $P<0.001$ ). In all seven group I baboons, uniform C3 localization was observed in infarct sites by direct immunofluorescence but appeared in mosaic patterns in intermediate sites. C3 was not demonstrated in any normal sites, nor in any site from group II baboons. Additional studies on baboons killed at earlier times after ligation indicated that C3 was localized focally on swollen myocytes in infarct sites as early as $4 \mathrm{~h}$ after coronary ligation. These results strongly implicate the active participation of the complement
\end{abstract}

This study was presented in preliminary form at the National Meeting of the American Society of Clinical Investigation 3 April 1978, Washington, D. C. and appeared in abstract form in 1978 (Clin. Res. 26: 484A).

Address reprint requests to Dr. O'Rourke.

Received for publication 29 February 1980 and in revised form 7 July 1980. system of inflammatory proteins in the pathogenesis of myocardial tissue injury following coronary occlusion.

\section{INTRODUCTION}

The major cause of death from myocardial infarction in hospitalized patients is left ventricular failure (1). Since the amount of infarcted tissue is an important determinant of left ventricular dysfunction, therapeutic interventions to limit the extent of myocardial necrosis after infarction have been proposed as a means of reducing the high mortality from coronary artery disease (2). Myocardial necrosis following coronary artery occlusion is due to an initial autolytic and possibly subsequent heterolytic myocardial cell injury. The initial autolytic tissue damage is due to diminished oxygen and substrate delivery. Later, heterolytic injury of myocardial tissue likely occurs in association with inflammatory cell infiltration.

Several studies have implicated the complement system of inflammatory plasma proteins as an important factor in the evolution of infarction. Hill and Ward (3) demonstrated that the early neutrophilic infiltration after experimental myocardial infarction in rats was reduced significantly by the prior administration of purified cobra venom factor that depletes the third component of complement (C3). More recently, Maroko et al. have reported that cobra venom factor $(\mathrm{CVF})^{1}$ administration reduced the extent of myocardial necrosis 1,2 , or $21 \mathrm{~d}$ after infarction as assessed by regional creatine kinase activity or postmortem measurements of infarct size in both dogs and rats $(4,5)$.

Previously, we documented significant decreases in the serum levels of the first four components of human complement $(\mathrm{Cl}, \mathrm{C} 4, \mathrm{C} 2$ and $\mathrm{C} 3)$ in patients during the first $72 \mathrm{~h}$ after myocardial infarction (6). Additional

\footnotetext{
${ }^{1}$ Abbreviation used in this paper: CVF, cobra venom factor.
} 
in vitro studies demonstrated that human heart subcellular membrane constituents, particularly mitochondria membranes, activated the same four components of human complement (6) by initiation of both the classical and alternative complement pathways (7). In these in vivo and in vitro studies, complement activation occurred by an antibody-independent mechanism.

Because C3 activation is pivotal for complementdependent acute inflammatory processes, the present investigation was designed to determine whether activation and localization of C3 occurred in situ in ischemic myocardium after coronary artery ligation. In addition, we sought to determine the effects of prior C3 depletion by CVF on myocardial necrosis after coronary artery ligation. In the present study, we used a baboon myocardial infarction model instead of the nonprimate species used by other investigators for the following reasons. First, both normal baboon and man lack complement-fixing anti-heart autoantibodies (6) that occur with a high incidence in normal rats and dogs (8). Thus, the baboon can be used to study the antibody-independent complement activation and subsequent localization in ischemic myocardium. Second, we have demonstrated that baboon complement components, including $\mathrm{C} 3$, immunochemically and functionally are indistinguishable from those of man, therefore permitting the utilization of many invaluable and highly specific immunohistologic probes (see Methods).

\section{METHODS}

14 baboons were included in this study. Group I consisted of seven baboons that were killed $24 \mathrm{~h}$ after ligation of the distal left anterior descending coronary artery. Group II consisted of seven baboons that were depleted of $\mathrm{C} 3$ by the administration of purified CVF (500 U/kg, i.p.) $24 \mathrm{~h}$ before coronary ligation and were killed $24 \mathrm{~h}$ after ligation.

All baboons were sedated by the intramuscular injection of ketamine $\mathrm{HCl}(10 \mathrm{mg} / \mathrm{kg}$ ) after immobilization in a "squeeze cage." After endotracheal intubation, the animals were placed on a closed ventilator system containing $99 \%$ oxygen and $0.6-0.8 \%$ halothane. The thorax was entered through the fifth intercostal space and the heart was suspended in a pericardial cradle to clearly visualize the anterior aspect of the left ventricle. The left anterior descending coronary artery was dissected free at its midportion, distal to the first major diagonal branch, and a mersiline tie was placed loosely around it for the purpose of subsequent occlusion. 12-18 anatomically identified sites on the anterior surface of the left ventricle were selected at the onset of each experiment before coronary artery ligation for recording unipolar epicardial electrocardiograms (ECG) in the area supplied by the artery to be occluded as well as areas far removed from it. A detailed drawing relating the ECG sites to the coronary arteries, veins, and other cardiac structures was prepared and used for electrode placement during serial epicardial ECG mapping and for subsequent tissue sampling. The method used was essentially identical to that introduced by Maroko et al. (9). $6 \mathrm{~h}$ after the coronary artery ligation, the chest was closed in layers and the animal was allowed to recover.

The epicardial electrode utilized was $15 \mathrm{~mm}^{2}$ copper cylinder containing a saline-soaked cotton wick connected to the precordial " $V$ " lead. Because of the large area of the electrode, small variations in its placement did not change the configuration of repeated recordings. The input impedance of the recorder DC amplifier was 10 megaohms and the frequency response of the system was $\pm 0.5 \mathrm{~dB}$ from 0.05 to $70 \mathrm{~Hz}$.

After a control epicardial ECG and during six limb lead ECG monitoring, the left anterior descending coronary artery was ligated at its mid-portion. Subsequent epicardial ECG were recorded 15 and $30 \mathrm{~min}$ after coronary occlusion at the same anatomic epicardial sites. In serial ECG mapping for $6 \mathrm{~h}$ after coronary artery ligation in 36 baboons, including those in this study, maximum ST-segment elevation occurred in the first $30 \mathrm{~min}$ after occlusion. Since there was no difference in the designation of sites at 15 and $30 \mathrm{~min}$, only the 15-min data will be discussed.

In this study, an infarct site was defined as a region of the myocardium showing greater than $2 \mathrm{mV}$ of ST-segment elevation at $15 \mathrm{~min}$ after coronary artery ligation. ST-segments were measured at a point $0.08 \mathrm{~s}$ after the intrinsicoid deflection and only in sites where the QRS complex did not exceed $0.065 \mathrm{~s}$. In the group I baboons all but one of the infarct sites showed at least a $50 \%$ reduction in $\mathrm{R}$-wave amplitude or the formation of $Q$-waves at the time of death. Control sites were selected where there was neither elevation nor depression of the ST-segments at $15 \mathrm{~min}$ post-coronary ligation and preservation of R-waves at the time of death. These sites always were remote from the infarct zone (see below). Intermediate zone sites usually showed ST-segment depression $15 \mathrm{~min}$ postligation and exhibited a variable reduction in R-wave amplitude at $24 \mathrm{~h}$.

The extent of the infarction also was determined using the method described by Bruyneel (10). This was accomplished by repeatedly moving the cotton wick electrode from the area of unequivocal infarction towards the uninvolved areas and observing the locations where the epicardial ECG pattern changed (Fig. 1). The border of acute injury and the intermediate zone were recorded on the detailed drawing of the left ventricle.

In all 14 baboons, systemic arterial pressure was monitored through a femoral arterial catheter using a P23Db pressure gauge (Statham Instruments, Inc., Div. Gould Inc., Oxnard, Calif.) with recordings made before coronary artery ligation and at 15 -min intervals for the $6 \mathrm{~h}$ after ligation. Additionally, lead-II electrocardiograms were monitored throughout the period of observation with recordings every $15 \mathrm{~min}$ for determining heart rate. In three group I and three group II baboons, a thermodilution, flow-directed No. 7 French balloon catheter (Electronics for Medicine, Inc., White Plains, N. Y.) was passed from the femoral vein into the pulmonary artery. In these six baboons pulmonary artery and pulmonary

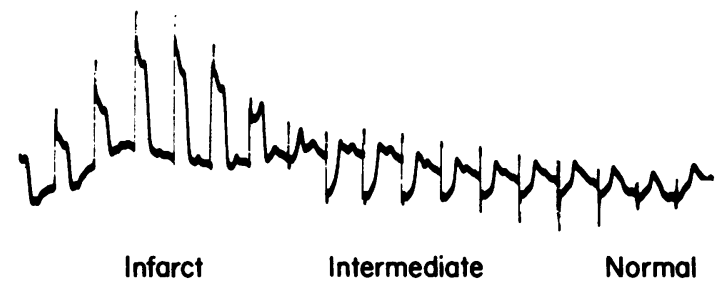

FIGURE 1 Continuous epicardial ECG recording as the electrode is moved from the infarct area to a normal area. 
capillary wedge pressures were monitored during the $6 \mathrm{~h}$ after coronary artery ligation, and thermodilution cardiac outputs were obtained in triplicate (Dye/Thermal Dilution Computer, model DTCCO-07; Electronics for Medicine, Inc.) at $30 \mathrm{~min}$, $1,2,4$, and $6 \mathrm{~h}$.

At the time of killing, the baboons were anesthetized, the chest was opened, and epicardial ECG mapping was performed as described above. The heart then was excised, washed in physiologic saline, and transmural biopsies $(4 \mathrm{~mm}$ Diam) were obtained from all the previously mapped ECG sites and were processed as follows. Each transmural biopsy was divided into three pieces that contained epicardium and endocardium for determination of creatine kinase content, for C3 localization by immunofluorescence, and for light microscopic examination. The tissue samples for C3 localization were placed in OCT (Ames Co., Elkhart, Ind.), immediately quick-frozen in a dry ice-acetone bath and stored at $-70^{\circ} \mathrm{C}$. The tissues for histologic assessment were fixed in $10 \%$ buffered formalin, $\mathrm{pH} \mathrm{7.4}$, and subsequently embedded in paraffin by routine procedures.

Myocardial creatine kinase content of the ECG mapped sites (international units per milligram protein) was estimated by the following procedure. Each transmural tissue sample was immediately placed in $5 \mathrm{ml}$ of $0^{\circ} \mathrm{C}$ buffer $(50 \mathrm{mM}$ disodium piperazine $-N, N^{\prime}$-bis-2-ethane sulfonic acid, $1 \mathrm{mM}$ EDTA, and $1 \mathrm{mM}$ dithiothreitol, $\mathrm{pH} \mathrm{6.8)}$ and homogenized using a Polytron tissue disintegrator (Brinkmann Instruments, Inc., Westbury, N. Y.) at setting 5 for $15 \mathrm{~s}$. The homogenate was centrifuged at $15,000 \mathrm{~g}$ for $10 \mathrm{~min}$. An aliquot of the supernate was used in the assay for creatine kinase and the remainder was frozen for subsequent protein determination (11). Total creatine kinase was measured, utilizing the assay procedure of Rosalki (12).

Immunoreactive $\mathrm{C} 3$ on $4-\mu \mathrm{m}$ frozen sections was assessed by direct immunofluorescence. Immediately after thawing, the frozen sections were washed six times, $10 \mathrm{~min}$ each, at $4^{\circ} \mathrm{C}$ in $0.15 \mathrm{M} \mathrm{NaCl}$ containing $0.01 \mathrm{M}$ EDTA. This procedure was utilized to minimize possible artifactual complement activation within the sections and to remove loosely bound plasma proteins. Subsequently, the sections were washed in phosphate-buffered saline $(0.14 \mathrm{M} \mathrm{NaCL}$ containing 0.01 sodium phosphate, $\mathrm{pH} 7.2$ ) for $10 \mathrm{~min}$ and then incubated at room temperature for $30 \mathrm{~min}$ with a fluorescein conjugated IgG fraction of monospecific goat anti-human C3 antibody (Atlantic Antibodies, Westbrook, Maine). This and four other monospecific anti-human C3 antisera demonstrated complete immunochemical identity between human and baboon C3 as assessed by Ouchterlony gel-diffusion analysis. Adjacent serial sections were treated with either fluorescein conjugated normal goat IgG, as a control for nonspecific antibody binding, or anti-human albumin (N. E. Chappel Laboratories, Inc., Cochranville, $\mathrm{Pa}$.), the latter to assess for nonspecific diffusion of plasma proteins in to the affected myocardium. The sections then were washed three times with phosphate-buffered saline and wet-mounted under $10 \%$ glycerol-saline. Fluorescence microscopy was performed on a Zeiss microscope (Carl Zeiss, Inc., N. Y.) with a darkfield condenser utilizing a Quartz-Halogen light source with an excitation filter of 450-490 nM and barrier filter of $530 \mathrm{nM}$ (Quartz Products Corp., Plainfield, N. J.). Routine tissue controls included sections of infarcted myocardium and sections of normal, uninfarcted myocardium obtained from complementintact baboons.

For light microscopy, 4- $\mu \mathrm{m}$ paraffin sections were prepared from the formalin fixed tissue and were stained with hematoxylin and eosin ( $\mathrm{H}$ and $\mathrm{E}$ ) and were evaluated to estimate the extent of myocardial injury as described by Maroko et al. (13).
CVF was purified by a modification of a procedure described by Cochrane et al. (14). $10 \mathrm{~g}$ of Naja naja Kaouthia cobra venom (Biologicals Unlimited, Inc., Baltimore, Md.) were dissolved in $0.01 \mathrm{M}$ phosphate buffer, $\mathrm{pH} 7.0$ containing $0.1 \mathrm{M} \mathrm{NaCl}$ at $37^{\circ} \mathrm{C}$. DEAE Sephadex G-50 $(250 \mathrm{ml}$ of a slurry in the same buffer) was added to the cobra venom and the entire mixture layered onto a $2.5-\mathrm{cm}$ Diam column $(600 \mathrm{ml}$ bed vol) at $4^{\circ} \mathrm{C}$. The column was washed until the effluent contained no detectable protein (optical density of 0 at 280 $\mathrm{nM}$ ) to elute the neurotoxin. The CVF subsequently was eluted with $0.01 \mathrm{M}$ phosphate buffer, $\mathrm{pH} 7.0$, containing $0.15 \mathrm{M} \mathrm{NaCl}$. The column fractions were assayed for anticomplementary activity and the active fractions were pooled and concentrated. The anticomplementary activity of CVF was quantitated by a slight modification of the procedure outlined by Cochrane and co-workers (14). Briefly, $0.10 \mathrm{ml}$ of doubling dilutions of CVF were added to $0.50 \mathrm{ml}$ of pooled, normal human serum diluted 1:20. The mixture was incubated at $37^{\circ} \mathrm{C}$ for $30 \mathrm{~min}$ and $0.40 \mathrm{ml}$ of sensitized sheep erythrocytes $\left(\mathrm{EA}, 5 \times 10^{8} \mathrm{EA} / \mathrm{ml}\right.$ ) then were added and incubated with shaking for an additional $30 \mathrm{~min}$ at $37^{\circ} \mathrm{C}$. Following the addition of $2 \mathrm{ml}$ ice-cold saline and removal of the unlysed EA by centrifugation, the $50 \%$ hemolytic end-point was determined spectrophotometrically. $1 \mathrm{U}$ of CVF was defined as the amount required to reduce the hemolytic activity of the $1: 20$ dilution of human serum by $50 \%$.

Subsequently, the CVF was purified further by molecular seive column chromatography using Sephadex G-200. In order to inactivate possible contaminating phospholipase $\mathbf{A}_{2}$, the purified CVF then was treated with $p$-bromphenacyl bromide according to the procedure of Roberts et al. (15). On sodium dodecyl sulfate (SDS) polyacrylamide gels, this CVF was a single band and had $1 \mathrm{U} / 1-2 \mu \mathrm{g}$ protein sp act.

$500 \mathrm{U} \mathrm{CVF} / \mathrm{kg}$ body wt i.p. were injected in baboons. This procedure resulted in a reduction of the C3 levels from $\sim 200,000$ hemolytic $\mathrm{U} / \mathrm{ml}$ serum to $<100 \mathrm{U} / \mathrm{ml} 24 \mathrm{~h}$ after CVF treatment. This dose of CVF was utilized since we had observed that lower doses (i.e., $250 \mathrm{U} \mathrm{CVF} / \mathrm{kg}$ ) administered intraperitoneally in some instances only reduced C3 levels by $70-90 \%$. Hemolytic C3 levels were determined as previously described (6). The functional C3 assays, utilizing cellular intermediates and complement reagents of human origin, indicated complete functional compatibility with baboon C3 since cotitration of human and baboon C3 gave virtually identical slopes when plotted by the von Krogh equation. In addition the levels of hemolytic C3 in baboon sera observed in the present studies were remarkably comparable with the C3 levels in man (6).

Statistical evaluation of the differences in creatine kinase content between infarct, intermediate, and normal zones within a group and between groups was determined by the Student's $t$ test (16). In the case of serial hemodynamic measurements, a two-way analysis of variance for repeated measurements was performed and a Dunnet's test (17) was used to identify individual differences. The chi-square test was used to compare the ST-segment and R-wave mapping in the nontreated and CVF-treated baboons (18).

\section{RESULTS}

Effect of C3 depletion upon the extent of myocardial injury $24 h$ after coronary artery ligation. In group I baboons, the creatine kinase content and histologic findings in infarct sites were compared with the normal sites. As shown in Table I, myocardial creatine kinase content in infarct sites $12.6 \pm 0.92(\mathrm{SE}) \mathrm{IU} / \mathrm{mg}$ protein 
was significantly reduced $(P<0.001)$ as compared with the normal sites $(24.4 \pm 0.75 \mathrm{IU} / \mathrm{mg}$ protein). Histologically, myocytes in infarct sites were uniformly shrunken and shared various degenerative nuclear changes (pyknosis, karyolysis, and karyorrhexis). As anticipated, the six or so layers of cells immediately beneath the endocardium were spared these changes. Intermediate sites histologically showed a lesser and highly variable degree of change and had a significantly greater content of creatine kinase $(19.0 \pm 1.25 \mathrm{IU} / \mathrm{mg}$ protein) as compared with the infarct sites $(P<0.001)$. Nevertheless, the creatine kinase content in the intermediate sites was significantly less when compared to the normal sites $(P<0.025)$.

In group II (CVF-treated) baboons, the myocardial creatine kinase content in the infarct sites $(16.9 \pm 0.81$ $\mathrm{IU} / \mathrm{mg}$ protein) was significantly less $(P<0.001)$ as compared with the normal sites $(24.1 \pm 0.76 \mathrm{IU} / \mathrm{mg}$ protein). However, in contrast to group I, the intermediate sites did not show a significant reduction in creatine kinase when compared with the normal sites $(P<0.95)$.

Although there was no significant difference in the creatine kinase content of the normal sites between group I and II, there was significantly less creatine kinase depletion in the infarct sites of group II (CVFtreated) baboons when compared with the group I animals $(33.7 \pm 4.6 \%$ and $51.4 \pm 1.8 \%)$ depletion, respectively $(P<0.001)$.

Infarct and intermediate sites of group I and II were compared histologically. The most striking histologic difference between these two groups of animals was the absence of significant neutrophil infiltration in the cobra venom-treated baboons. Although the extent of myocardial necrosis in infarct sites in the group II baboons was diminished as compared with group I, the histologic patterns were extremely variable between animals in both groups. Thus, in contrast to the creatine kinase data (see above) there were no significant differences between group I and group II baboons.

TABLE I

Myocardial Creatine Kinase Content from Normal, Infarct, and Intermediate Sites in Group I and II Baboons

\begin{tabular}{lccc}
\hline & Normal & Infarct & Intermediate \\
\hline Group I & $24.4 \pm 0.75^{*}$ & $12.6 \pm 0.92$ & $19.0 \pm 1.25$ \\
& $(n=36)$ & $(n=34)$ & $(n=29)$ \\
Group II & $24.1 \pm 0.76$ & $16.9 \pm 0.81$ & $24.2 \pm 1.61$ \\
& $(n=50)$ & $(n=30)$ & $(n=12)$ \\
& NS & $P<0.025 \ddagger$ & $P<0.001$ \\
\hline
\end{tabular}

* International units of creatine kinase per milligram protein, mean $\pm \mathrm{SE}, n$, number of sites within a group.

$\downarrow P$ value determined by Student's $t$ test between groups I and II.
Several other differences between groups I and II merit comment. Of the 29 intermediate sites from the group I animals, eight (28\%) subsequently evolved to infarction as determined by $>20 \%$ reduction in creatine kinase activity. In contrast, only 1 of the 12 intermediate sites (8\%) in group II baboons subsequently evolved to infarction, which was significantly different from the group I animals $\left(\mathrm{X}^{2}=3.58, P<0.05\right)$. In addition, although all seven group I baboons had intermediate sites defined by epicardial ECG, only four of the seven group II baboons had intermediate sites. Of even greater significance, was the observation that 8 of the 30 sites (27\%) with marked ST-segment elevation early after coronary artery ligation in group II animals did not show a subsequent reduction in $R$-wave amplitude, the formation of Q-waves, or a reduction in creatine kinase activity at $24 \mathrm{~h}$. However, only 1 of the 34 sites with $>2 \mathrm{mV}$ ST elevation in the group I baboons was not unequivocally infarcted $24 \mathrm{~h}$ later. This difference between the two groups was statistically different $\left(\mathrm{X}^{2}=6.6, P<0.025\right)$.

Hemodynamic measurements. There were no differences between group I and II in the control heart rate or in the heart rates measured 15 and $30 \mathrm{~min}, 1$, 2,4 , and $6 \mathrm{~h}$ after coronary artery ligation (Table II). In both groups of animals, the mean arterial pressures fell significantly $(P<0.005)$ within $15 \mathrm{~min}$ after coronary artery ligation. The decrease in mean arterial pressure persisted in both groups during the $6 \mathrm{~h}$ of observation $(P<0.05)$. However, the decrease in mean arterial pressures after coronary ligation was no different between the two groups of baboons at any point during the 6 -h period.

In the group I and group II baboons, the control cardiac outputs were similar $(80 \pm 7$ vs. $85 \pm 8 \mathrm{ml} / \mathrm{kg})$. Cardiac output decreased similarly in both groups of animals $30 \mathrm{~min}$ after coronary artery occlusion (69 \pm 6 vs. $67 \pm 4 \mathrm{ml} / \mathrm{kg}$ ) and returned to control levels at $6 \mathrm{~h}(77 \pm 15 \mathrm{vs} .79 \pm 17 \mathrm{ml} / \mathrm{kg})$. In both group I and II animals, the control pulmonary artery wedge pressures were nearly the same ( $9 \pm 3$ vs. $8 \pm 2 \mathrm{~mm} \mathrm{Hg}$ ), increased within $15 \mathrm{~min}$ after ligation ( $13 \pm 3$ vs. $12 \pm 2 \mathrm{~mm} \mathrm{Hg}$ ) and were unchanged $6 \mathrm{~h}$ later $(12 \pm 3 \mathrm{vs} .11 \pm 4 \mathrm{~mm} \mathrm{Hg})$.

Localization of $\mathrm{C} 3$ in ischemic myocardium. In all seven group I baboons (non-CVF-treated), uniform C3 localization was observed in every infarct site by direct immunofluorescence. In transmural sections from these sites, C3 was extensively localized in most myocardial fibers particularly those fibers having a shrunken and wavy appearance (Fig. 2a). The localization was most intense in the endocardial half of the sections. Of interest, C3 rarely was detected in myocardial fibers immediately adjacent to the endocardium (Fig. 2b). C3 also was observed in intermediate sites; however, in contrast to the infarction sites, C3 appeared as a mosaic pattern (Fig. 2c) with $\mathrm{C} 3$ localization on 
TABLE II

Heart Rate and Mean Arterial Blood Pressure in Group I and II Baboons

\begin{tabular}{|c|c|c|c|c|c|c|c|}
\hline & Control & $15 \mathrm{~min}$ & $30 \mathrm{~min}$ & $1 \mathrm{~h}$ & $2 \mathrm{~h}$ & $4 \mathrm{~h}$ & $6 \mathrm{~h}$ \\
\hline \multicolumn{8}{|c|}{ Heart rate (beats/min) } \\
\hline Group I & $91 \pm 5^{*}$ & $91 \pm 6$ & $91 \pm 5$ & $87 \pm 3$ & $88 \pm 3$ & $88 \pm 3$ & $85 \pm 4$ \\
\hline Group II & $86 \pm 6$ & $88 \pm 6$ & $85 \pm 5$ & $85 \pm 6$ & $85 \pm 6$ & $86 \pm 5$ & $84 \pm 5$ \\
\hline \multicolumn{8}{|c|}{ Arterial pressure $(\mathrm{mm} \mathrm{Hg})$} \\
\hline Group I & $79 \pm 5$ & $68 \pm 4 \ddagger$ & $70 \pm 2 \ddagger$ & $68 \pm 4 \ddagger$ & $73 \pm 3 \S$ & $71 \pm 2 \ddagger$ & $74 \pm 4$ \\
\hline Group II & $81 \pm 4$ & $69 \pm 3 t$ & $72 \pm 2 \ddagger$ & $72 \pm 2 \ddagger$ & $72 \pm 2 \ddagger$ & $70 \pm 3 \ddagger$ & $75 \pm 3^{\prime \prime}$ \\
\hline
\end{tabular}

obviously abnormal myocytes but not on fibers with normal morphology. On adjacent sections of infarct, intermediate, and normal sites, no positive fluorescence
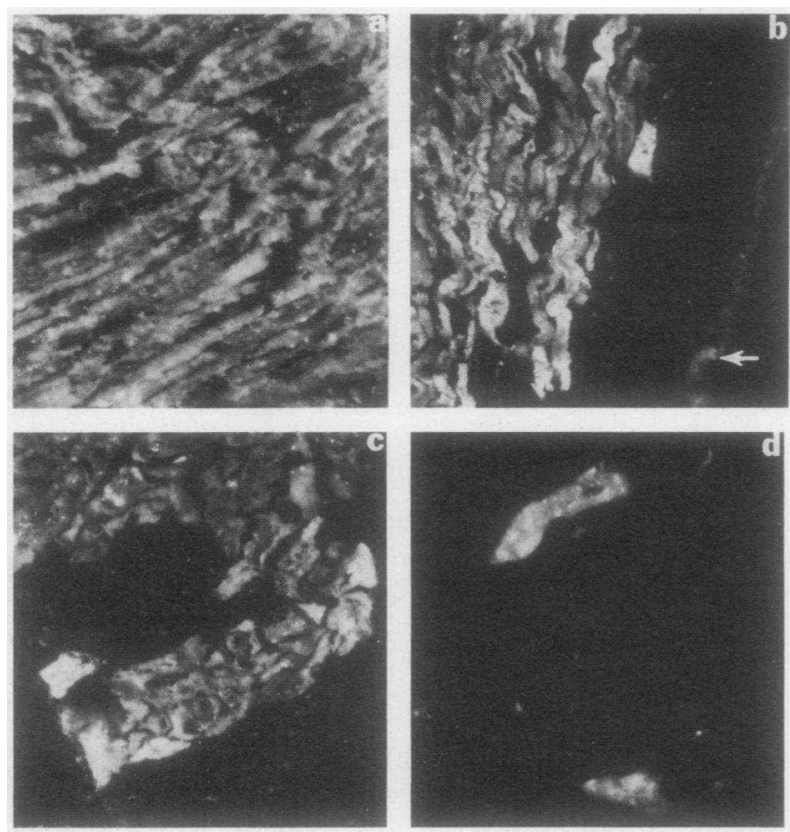

FIGURE 2 Direct immunofluorescent localization of C3 in baboon myocardium. (a) C3 localization in an infarct site obtained $24 \mathrm{~h}$ after coronary artery ligation. C3 immunofluorescence includes all myocardial fibers in these areas. $\times 265$. (b) C3 localization in an infarct site obtained $24 \mathrm{~h}$ after coronary artery ligation. The intense C3 immunofluorescence of shrunken myocardial fibers (left) does not extend into several layers of fibers immediately adjacent to the endocardium that commonly demonstrate faint, nonspecific autofluorescence in infarct as well as in normal myocardium (arrow). $\times 265$. (c) C3 localization in an intermediate site obtained $24 \mathrm{~h}$ after coronary artery ligation. In this longitudinal section of myocardial muscle, C3 is localized in some myocardial fibers. $\times 265$. (d) C3 localization in a myocardial infarct site (defined by epicardial ECG mapping) obtained $4 \mathrm{~h}$ after coronary artery ligation. C3 is present in isolated, swollen myocardial fibers. $\times 690$. occurred when fluorescein conjugated normal goat IgG or anti-human albumin were used. C3 was not demonstrated in normal sites.

CVF treatment (group II baboons) abrogated the localization of $\mathrm{C} 3$ in both infarct and intermediate sites; and, as in the group I animals, C3 was not present in normal sites. In addition, C3 was not localized in myocardial tissue from two sham-operated, non-CVFtreated baboons.

Additional studies were conducted to estimate the temporal localization of C3 after coronary artery ligation. These studies included three baboons sacrified $4 \mathrm{~h}$, two at $6 \mathrm{~h}$ and one at $12 \mathrm{~h}$ after ligation. In all of the animals studied, C3 was localized in the infarct sites. A fluorescence micrograph showing C3 localization within an infarct site (defined by epicardial ECG mapping) from a baboon sacrificed at $4 \mathrm{~h}$ is shown in Fig. 2d. C3 was localized focally on and within swollen myocytes, exclusively in the endocardial half of the transmural section. Adjacent cells with normal morphology did not show significant immunofluorescence. Similar observations were made in the two 6-h baboons. In the baboon killed $12 \mathrm{~h}$ after coronary ligation, C3 localized on small clusters of myocytes in infarct sites. However, this pattern of C3 localization was less extensive than that observed in intermediate sites obtained from baboons killed at $24 \mathrm{~h}$ after coronary artery ligation (Fig. 2b).

\section{DISCUSSION}

In this study unipolar epicardial ECG mapping was utilized to define areas of severe myocardial ischemia after coronary artery ligation and to identify normal sites. This technique was not used to quantitate the extent of myocardial infarction because of the well recognized limitations with this method $(19,20)$. However, these mapping procedures in the non-CVF treated (group I) baboons predicted subsequent severe myocardial necrosis, $24 \mathrm{~h}$ later. Other investigators pre- 
viously have demonstrated that the ST-segment elevation recorded $15 \mathrm{~min}$ after coronary occlusion is an excellent predictor of epicardial Q-waves 6 and $24 \mathrm{~h}$ later (21). Our results are in agreement with these studies.

Of 34 mapped sites showing $>2 \mathrm{mV}$ ST-segment elevation at $15 \mathrm{~min}$ postligation in the group I baboons, 97\% showed unequivocal evidence of severe myocardial necrosis as determined by reduction in the tissue levels of creatine kinase content $24 \mathrm{~h}$ after ligation. In addition, these sites showed a reduction in R-wave amplitude by at least $50 \%$, usually with the formation of Q-waves. By contrast, infarct sites, as determined by epicardial ECG mapping, in the C3depleted (group II) baboons frequently did not show marked reduction in $\mathrm{R}$-wave amplitude or $\mathrm{Q}$-wave development $24 \mathrm{~h}$ later. These data suggest that prior depletion of $\mathrm{C} 3$ with CVF reduces the extent of myocardial necrosis at $24 \mathrm{~h}$. These effects were not only seen in infarct sites but in intermediate sites as well.

The apparent preservation of ischemic myocardium by CVF could not be explained by differences in hemodynamics between the two groups of animals. There was no difference during the $6 \mathrm{~h}$ of monitoring between the two groups in either heart rate or systemic arterial pressure. In three animals within each group, the increase in pulmonary artery wedge pressures and the decreased in cardiac output after coronary artery ligation were similar. This is consistent with the previous observations in dogs by Maroko et al. (4). In addition, these investigators could not explain the preservation of myocardium due to CVF by any differences in cardiac output, left ventricular pressure, or left ventricular $d P / d t$ between the CVF-treated and untreated animals. Furthermore, they were unable to demonstrate any differences in regional myocardial blood flow after coronary artery ligation in control as compared with C3-depleted dogs. Thus, our study and that by Maroko et al. (4) suggest that C3 depletion with CVF may influence the second or heterolytic phase of myocardial tissue injury induced by ischemia. However, the possibility that C3 depletion affects regional coronary blood flow in our baboon model cannot be excluded.

The present study and that by Maroko et al. (4), strongly implicate the active participation of the complement system of inflammatory proteins in the pathogenesis of myocardial tissue injury following coronary artery occlusion. These conclusions are strengthened by our finding of significant C3 localization within ischemic myocardium as early as $4 \mathrm{~h}$ after coronary artery ligation (Fig. 2d). With time, the degree of C3 localized within the affected area increased, and by $24 \mathrm{~h}$ all myocytes within the infarcted areas showed intense $\mathrm{C} 3$ localization (Fig. 2a, 2b). However, the precise subcellular distribution of $\mathrm{C} 3$ must await ultrastructural verification. Of interest was the finding of mosaic patterns of C3 localizaton in the intermediate sites where characteristically C3 localization occurred on cells with apparent normal morphology (Fig. 2c). In contrast with our studies, Maroko et al. (4) failed to detect C3 in two dogs $24 \mathrm{~h}$ after coronary artery ligation. The explanation for the discrepancy between our findings and theirs is unknown. However, the difference in experimental animals used in the two studies must be considered.

The mechanism for the complement-mediated injury of the ischemic myocardium presently can only be a matter of speculation. It is likely that complement activation, at least through $\mathrm{C} 3$, had occurred in the infarcted group I baboons. Moreover, as reported previously by Hill and Ward (3), the neutrophilic infiltration into infarcts in C3-depleted baboons (group II) was strikingly less or absent as compared with the complement-intact, group I baboons. These latter observations strongly suggest that activation of the terminal complement sequence had occurred since C5a is the primary neutrophil chemotatic factor derived from the complement system. Thus, one could expect the release of various vasoactive peptides (e.g., the C4a, and C3a, and C5a anaphylatoxins) and membrane localization of $\mathrm{C} 3 \mathrm{~b}$. Anaphylatoxin release could affect regional perfusion of the ischemic myocardium or C5a and bound C3b could modulate neutrophil infiltration and adherence with subsequent release of injurious neutrophil lysosomal granules and production of toxic oxygen radicals. Our preliminary evidence for the temporal localization of $\mathrm{C} 3$ suggests that significant complement activation does not occur until 4-6 h following coronary artery occlusion. Therefore, once the molecular mechanism governing the activation of complement in the ischemic myocardium are elucidated, suitable therapeutic interventions could be developed for effectively reducing the amount of complement-dependent myocardial tissue injury.

\section{ACKNOWLEDGMENTS}

The authors wish to thank Mr. Donald Watkins, Ms. Pamela Stapleton, Mr. Shou-san Tung, and Ms. Cindy Franks for their invaluable assistance. This work was supported by U. S. Public Health Service grants HL 20394 and 07350.

\section{REFERENCES}

1. Page, D. L., J. B. Caulfield, J. A. Kaster, R. W. DeSanctis, and C. A. Sanders. 1971. Myocardial changes associated with cardiogenic shock. N. Engl. J. Med. 285: 133-137.

2. Maroko, P. R., and E. Braunwald. 1973. Modification of myocardial infarction size after coronary occlusion. Ann. Intern. Med. 79: 720-733.

3. Hill, J. H., and P. A. Ward. 1971. The phlogistic role of C3 leukotactic fragments in myocardial infarcts of rats. J. Exp. Med. 133: 885-900.

4. Maroko, P. R., C. B. Carpenter, M. Chiariello, M. C. 
Fishbein, P. Radvany, J. D. Knustman, and S. L. Hale 1978. Reduction by cobra venom factor of myocardial necrosis after coronary artery occlusion. J. Clin. Invest. 61: 661-670.

5. Maclean, D., M. C. Fishbein, E. Braunwald, and P. R. Maroko. 1978. Long-term preservation of ischemic myocardium after experimental coronary artery occlusion. J. Clin. Invest. 61: 541-551.

6. Pinckard, R. N., M. S. Olson, P. C. Giclas, R. Terry, J. T. Boyer, and R. A. O'Rourke. 1975. Consumption of classical complement components by heart subcellular membranes in vitro and in patients after acute myocardial infarction. J. Clin. Invest. 56: 740-750.

7. Giclas, P. C., R. N. Pinckard, and M. S. Olson. 1979. In vitro activation of complement by isolated human heart subcellular membranes. J. Immunol. 122: 146-151.

8. Pinckard, R. N., M. S. Olson, R. A. O'Rourke, J. D. Palmer R. E. Kelley, and S. Goldstein. 1971. Development of complement-fixing 19S, anti-heart mitochondria antibody, following myocardial infarction in dogs. Circ. Res. 19: 176-185.

9. Maroko, P. R., J. K. Kjekshus, B. E. Sobel, T. Watanabe, J. W. Covell, J. Ross, Jr., and E. Braunwald. 1971. Factors influencing infarct size following coronary artery occlusion. Circulation. 43: 67-82.

10. Bruyneel, K. J. 1975. Use of moving epicardial electrodes in defining ST-segment changes after acute coronary occlusion in the baboon. Relation to primary ventricular fibrillation. Am. Heart J. 89: 731-738.

11. Gornall, A. G., C. J. Bardawill, and M. M. David. 1949. Determination of serum proteins by means of the Biuret Reaction. J. Biol. Chem. 177: 751-766.

12. Rosalki, S. B. 1967. An Improved procedure for serum creatine phosphokinase determination. J. Lab. Clin. Med. 69: 696-670.

13. Maroko, P. R., P. Libby, B. E. Sobel, C. M. Bloor, H. D. Sybers, W. E. Shell, J. W. Covell, and E. Braunwald. 1972. The effect of glucose-insulin-potassium infusion on myocardial infarction following experimental coronary artery occlusion. Circulation. 45: 1160-1175.

14. Cochrane, C. G., H. J. Muller-Eberhard, and B. S. Aikin. 1970. Depletion of plasma complement in vivo by a protein of cobra venom. Its effects on various immunologic reactions. J. Immunol. 105: 55-69.

15. Roberts, M. F., R. A. Deems, T. Mincey, and E. Dennis. 1977. Chemical modification of the histidine residue in phospholipase $\mathrm{A}_{2}$ (Naja Naja). J. Biol. Chem. 252: 2405-2411.

16. Colton, T. 1974. Statistics in Medicine. Little, Brown \& Company, Boston. 131-136.

17. Croxton, F. E., and D. J. Cowden. 1939. Applied General Statistics. Prentice-Hall, Inc., Englewood Cliffs, N. J. $176-180$.

18. Colton, T. 1974. Statistics in Medicine. Little, Brown \& Company, Boston. 174-178.

19. Fozzard, H. A. 1976. ST-segment potentials and mapping. Theory and experiments. Circulation. 54: 533-537.

20. Holland, R. P., and H. Brooks. 1977. TQ-ST segment mapping. Critical review and analysis of current concepts. Am. J. Cardiol. 40: 110-129.

21. Hillis, L. D., J. Askinazi, E. Braunwald, P. Radvany, J. E. Muller, M. C. Fishbein, and P. R. Maroko. 1976. Use of changes in the epicardial QRS complex to assess interventions which modify the extent of myocardial necrosis following coronary artery occlusion. Circulation. 54: 591-598. 